\title{
Calculation of Pavement Engineering Quantities of Mountainous Highway in Feasibility Study Stage
}

\author{
Wei Zhang*, Xiaoyong Rao, Shanshan Zhang \\ Broadvision Engineering Consultants Co. Ltd., Kunming, Yunnan, China \\ *Corresponding Author.
}

\begin{abstract}
The reasonable estimation of the number of pavement works in the feasibility study stage of highway engineering construction project is one of the basis for the preparation of investment estimation. The selection of pavement structure layer and the calculation of thickness, the calculation of different terrain and pavement area is the main content of highway pavement quantity calculation in mountainous and hilly area. It is of great significance to select the correct calculation method according to different geological conditions. Through 10 engineering cases analysis, the paper analyzes the thickness and area calculation of the pavement structure of the mountain road. It is concluded that the pavement structure layer can be in the form of subbase + base + seal + surface layer. The influence of shoulder, subgrade retaining wall and middle separation zone should be considered in the calculation of pavement area.
\end{abstract}

Keywords: Pavement engineering, pavement structure layer, thickness design, pavement area calculation

\section{Introduction}

The feasibility study of highway construction project is a comprehensive research and demonstration work on the necessity, technical feasibility, economic rationality and implementation possibility of the project construction, which is the main basis for the decision-making of the construction project [1]. Investment estimation is an important part of engineering feasibility study report, one of the bases of technical feasibility, economic rationality and implementation possibility demonstration, and an important basis for construction project decision-making. Reasonable determination and control of project investment in feasibility study stage is an important work of construction project feasibility study. The preparation of investment estimation is based on the design documents of the project, comprehensive understanding of the construction conditions of the project site, mastering various basic data, correctly quoting indicators, charging standards, labor unit price, material and equipment price, The work is carried out in accordance with the Compilation Method for Investment Estimation of Highway Capital Construction Engineering and Estimation Index of Highway Engineering implemented at the present stage, as well as the provisions in line with the current relevant national and industrial standards.

The reasonable estimation of engineering quantity in engineering feasibility stage is the key work of feasibility study and the important basic data of investment estimation [2]. The engineering quantity in the feasibility stage of the project includes: estimation of the quantity of temporary works, subgrade works, pavement works, bridge and culvert works, tunnel works, crossing works, facilities along the line, greening and environmental protection works, other works, land use scale and demolition, etc [3]. The investment of pavement engineering occupies a large part in the investment estimation, especially in the low-grade highway. Reasonable estimation of pavement engineering quantity is one of the key works to determine and control engineering investment estimation [4].

The estimation of pavement engineering quantity in the feasibility stage of the project is reflected by compiling the estimation table of pavement engineering quantity, according to the relevant provisions of highway engineering implemented at this stage [5]. It is advocated to promote the standardization of engineering quantity estimation

ISSN: 0010-8189

(C) CONVERTER 2021

www.converter-magazine.info 
table in engineering feasibility stage. Standardization is beneficial to improve the efficiency of cost documentation. The standardization and standardization of cost documents is conducive to the whole process control of cost documents [6-9].

The standardization of the quantity table of highway pavement works in mountainous areas in the feasibility stage of the project requires systematic research on the characteristics of the project, the rules for the preparation of the project cost, the requirements of the Highway Engineering Estimation Index, the Design Specification of Cement Pavement, the Design Code of Asphalt Concrete Pavement and the quantity of similar projects in the projects already built. It is of great significance to study the standardization of pavement quantity table of mountain highway engineering in the feasibility stage of the project [10-12].

\section{Structure Layer and Distribution of Highway Pavement in Mountainous Area}

The engineering cost of pavement is generally calculated according to the type of pavement surface material. In the engineering feasibility stage, the compilation of pavement engineering quantity table first needs to know the type of pavement.

\subsection{According to the type of pavement material}

The engineering cost of pavement is generally calculated according to the type of pavement surface material. The classification of pavement surface materials is shown in Figure 1.

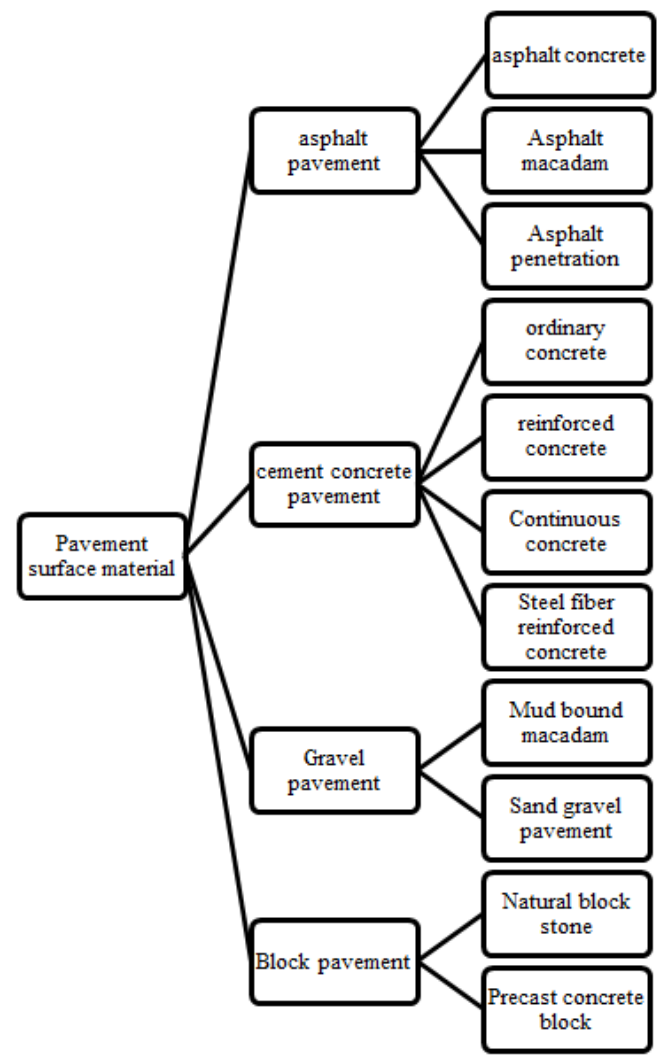

Fig 1: Classification of pavement materials

The pavement structure layer can be composed of surface layer, base layer, subbase layer, cushion layer and function layer. 
- Surface layer: the surface layer can be single layer, double layer or three layers.

- Base: the base can be single layer or double layer

- Subbase: subbase is a secondary load-bearing layer set under the base and bear repeated wheel loads together with surface course and base course. Therefore, the technical index requirements of subbase materials can be slightly lower than that of base course materials, and subbase can also be divided into upper and lower subbase.

- Cushion: the cushion is a structural layer set between the subbase and the soil foundation, which plays the role of drainage, waterproof, anti-freezing, anti-fouling, reducing the modulus ratio between layers and reducing the tensile stress of semi-rigid subbase. Cushion material can be selected. According to different materials, it can be divided into two categories: permeable cushion (granular material) and stable cushion. It is mainly composed of coarse sand, gravel, crushed stone, cinder, slag and other granular materials, as well as cement or lime cinder stability, lime fly ash stability and so on. All levels of highway should be set up according to the specific situation of the necessary structural layer, but for the third and fourth class highway, at least not less than two layers, that is, surface layer and base layer.

\subsection{Pavement thickness}

The empirical estimation method generally refers to the pavement engineering thickness of the built highway in the area where the project is located. The preliminary thickness is determined by calculation based on the traffic volume data.

The pavement thickness of some expressways and second-class highways in mountainous areas that have been opened to traffic are counted. When estimating the initial pavement thickness, the estimated quantity can be adjusted according to table 1 and table 2 .

Table 1 Statistical table of expressway pavement thickness in mountainous and hilly areas

\begin{tabular}{|c|c|c|c|c|c|c|c|c|}
\hline \multirow[t]{2}{*}{ Project name } & \multirow{2}{*}{$\begin{array}{l}\text { Subgr } \\
\text { ade } \\
\text { width } \\
\text { (m) }\end{array}$} & \multirow{2}{*}{$\begin{array}{c}\begin{array}{c}\text { Subbas } \\
\text { e }(\mathrm{cm})\end{array} \\
\text { Graded } \\
\text { crushed } \\
\text { stone }\end{array}$} & \multirow{2}{*}{$\begin{array}{c}\begin{array}{c}\text { Base } \\
(\mathrm{cm})\end{array} \\
\text { Cement } \\
\text { stabilized } \\
\text { macadam }\end{array}$} & \multirow{2}{*}{$\begin{array}{c}\text { Seal }(\mathrm{cm}) \\
\text { SBS modified } \\
\text { asphalt } \\
\text { synchronous } \\
\text { macadam }\end{array}$} & \multicolumn{3}{|c|}{ surface layer $(\mathrm{cm})$} & \multirow{2}{*}{$\begin{array}{c}\text { Total } \\
\text { thickne } \\
\text { ss of } \\
\text { paveme } \\
\text { nt }(\mathrm{cm})\end{array}$} \\
\hline & & & & & $\begin{array}{l}\text { AC-25 } \\
\text { coarse } \\
\text { grained } \\
\text { asphalt } \\
\text { concrete }\end{array}$ & $\begin{array}{c}\text { AC-20 } \\
\text { medium } \\
\text { grained } \\
\text { asphalt } \\
\text { concrete }\end{array}$ & $\begin{array}{l}\text { AC-13 } \\
\text { fine } \\
\text { grained } \\
\text { asphalt } \\
\text { concrete }\end{array}$ & \\
\hline Baolu highway & 25.5 & 20 & 39 & 0.6 & 8 & 6 & 4 & 77.6 \\
\hline Tenhou highway & 25.5 & 20 & 35 & 0.6 & 8 & 6 & 4 & 73.6 \\
\hline Nanjing highway & 25.5 & 20 & 38 & 0.6 & 8 & 6 & 4 & 76.6 \\
\hline Qulu highway & 33.5 & 20 & 40 & 0.6 & 8 & 6 & 4 & 78.6 \\
\hline Pingwen highway & 24.5 & 20 & 40 & 0.6 & 8 & 6 & 4 & 78.6 \\
\hline Heguan highway & 25.5 & 20 & 38 & 0.6 & 8 & 6 & 4 & 76.6 \\
\hline Xiahe highway & 25.5 & 10 & 40 & 0.6 & 8 & 6 & 4 & 78.6 \\
\hline Daigong highway & 24.5 & 20 & 40 & 0.6 & 8 & 6 & 4 & 78.6 \\
\hline $\begin{array}{c}\text { Xiangli highway } \\
\text { SJ1 }\end{array}$ & 24.5 & 20 & 39 & 0.6 & 8 & 6 & 4 & 77.6 \\
\hline $\begin{array}{c}\text { Xiangli highway } \\
\text { SJ2 }\end{array}$ & 24.5 & 20 & 50 & 0.6 & 8 & 6 & 4 & 88.6 \\
\hline
\end{tabular}

Table 2 Statistical table of pavement thickness of class II highway in mountainous and hilly areas

\begin{tabular}{|c|c|c|c|c|c|c|}
\hline Project name & $\begin{array}{c}\text { Subgrade } \\
\text { width }\end{array}$ & $\begin{array}{c}\text { Subbase } \\
(\mathrm{cm})\end{array}$ & $\begin{array}{c}\text { Base } \\
(\mathrm{cm})\end{array}$ & Seal $(\mathrm{cm})$ & surface layer $(\mathrm{cm})$ & $\begin{array}{c}\text { Total } \\
\text { thickness }\end{array}$ \\
\hline
\end{tabular}

ISSN: 0010-8189 


\begin{tabular}{|c|c|c|c|c|c|c|c|c|}
\hline & $(\mathrm{m})$ & $\begin{array}{c}\text { Graded } \\
\text { crushed } \\
\text { stone }\end{array}$ & $\begin{array}{c}\text { Cement } \\
\text { stabilized } \\
\text { macadam }\end{array}$ & $\begin{array}{c}\text { SBS } \\
\text { modified } \\
\text { asphalt } \\
\text { synchronous } \\
\text { macadam }\end{array}$ & $\begin{array}{c}\text { AC-25 } \\
\text { coarse } \\
\text { grained } \\
\text { asphalt } \\
\text { concrete }\end{array}$ & $\begin{array}{c}\text { AC-20 } \\
\text { medium } \\
\text { grained } \\
\text { asphalt } \\
\text { concrete }\end{array}$ & $\begin{array}{c}\text { AC-13 } \\
\text { fine } \\
\text { grained } \\
\text { asphalt } \\
\text { concrete }\end{array}$ & $\begin{array}{c}\text { of } \\
\text { pavement } \\
(\mathrm{cm})\end{array}$ \\
\hline ShangwuRoad & 12 & 20 & $\begin{array}{c}35 \text { (Other } \\
\text { sections) }\end{array}$ & 0.6 & 7 & - & 4 & 66.6 \\
\cline { 2 - 9 } & 20 & $\begin{array}{c}38 \text { (Town } \\
\text { section) }\end{array}$ & 0.6 & 7 & - & 4 & 69.6 \\
\hline $\begin{array}{c}\text { Manjin } \\
\text { highway }\end{array}$ & 10 & 20 & 35 & 0.6 & & 6 & 4 & 60.6 \\
\hline $\begin{array}{c}\text { Shuisui } \\
\text { highway }\end{array}$ & 12 & 15 & 32 & 0.6 & & 6 & 4 & 57.6 \\
\hline $\begin{array}{c}\text { Zhuanhong } \\
\text { highway }\end{array}$ & 10 & 15 & 36 & 0.6 & & 6 & 4 & 59.6 \\
\hline
\end{tabular}

Generally, the subbase + base + seal layer + surface layer structure is adopted for the subgrade section. For example, the asphalt concrete pavement is proposed to be adopted for Nanjing highway. The total thickness of the pavement is $76.6 \mathrm{~cm}$, and the thickness of each structural layer is $4 \mathrm{~cm}$ for AC-13 fine-grained asphalt concrete anti sliding layer, $6 \mathrm{~cm}$ for AC-20 medium grained asphalt concrete middle surface layer, $8 \mathrm{~cm}$ for AC-25 coarse-grained asphalt concrete lower layer, $6 \mathrm{~cm}$, Cement Stabilized Graded Crushed Stone Base $38 \mathrm{~cm}$, skeleton dense graded crushed stone layer $20 \mathrm{~cm}$. The hard shoulder structure layer is consistent with the same lane.

\section{Calculation of Road Surface Area in Mountainous Area}

In the feasibility stage, the pavement area of Expressway and first-class highway is generally calculated according to the integral subgrade. Conventional down Lane pavement and hard shoulder pavement adopt the same pavement structure, and the earth shoulder is hardened. The area of driving road surface is generally fixed, and the width of $25.5 \mathrm{~m}$ driving road surface is calculated as $2 * 3.75 * 2=15 \mathrm{~m}$. The shoulder area of driving road is calculated according to different road sections, and the curb area of the middle section is generally determined. Conventional down Lane pavement and hard shoulder pavement adopt the same pavement structure, and the earth shoulder is hardened. The area of driving road surface is generally fixed, and the width of $25.5 \mathrm{~m}$ driving road surface is calculated as $2 * 3.75 * 2=15 \mathrm{~m}$. The shoulder area of driving road is calculated according to different road sections, and the curb area of the middle section is generally determined.

\subsection{Shoulder pavement area of side ditch section}

The width of hard shoulder on the side of side ditch is $3.0 \mathrm{~m}$, and the part of earth shoulder is included in the scope of side ditch. As shown in Figure 2.

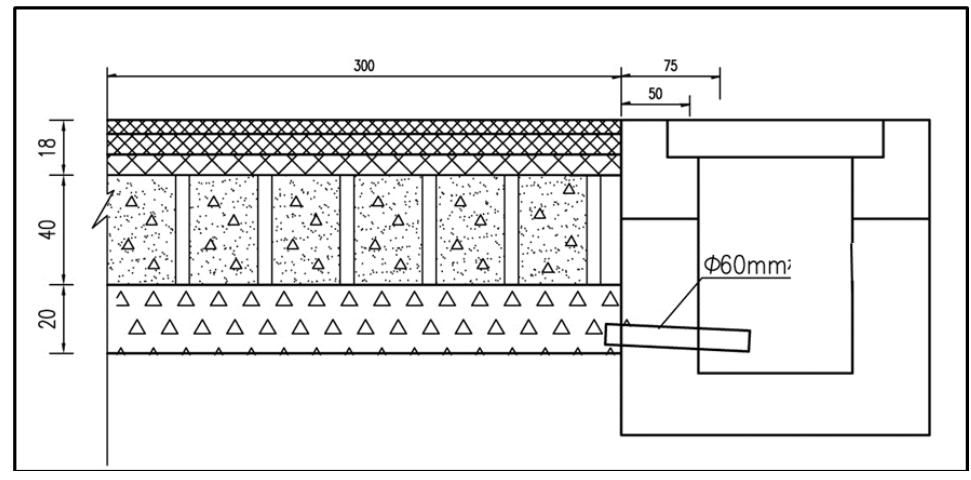

ISSN: 0010-8189

www.converter-magazine.info 
Fig 2: Side ditch section

The area of surface course, base course and subbase course is consistent, and the pavement area width of shoulder part is calculated as $3.0 \mathrm{~m}$.

3.2 Subgrade width $25.5 \mathrm{~m}$ the filling is set with shoulder wall

The construction of shoulder wall is shown in Figure 3.

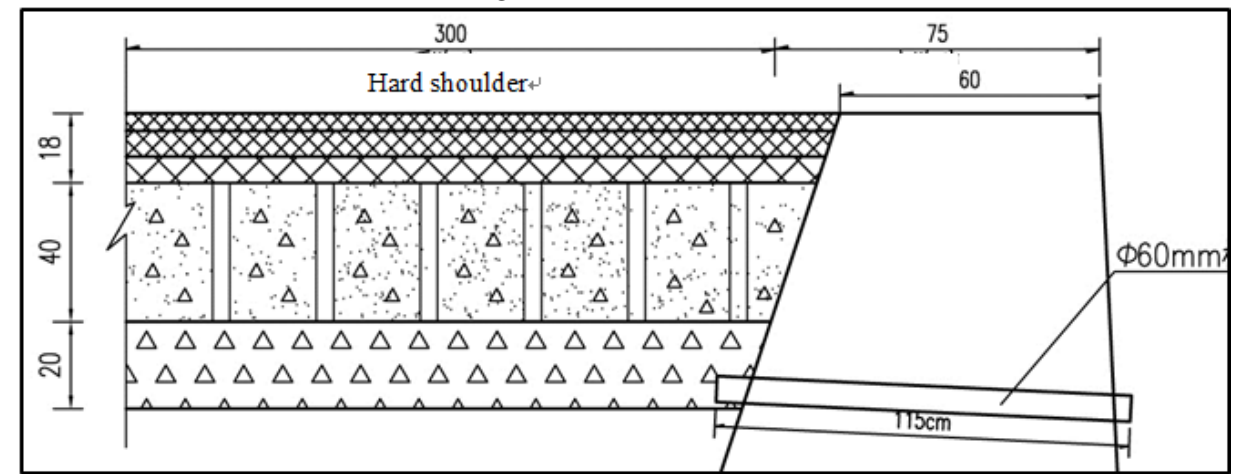

Fig 3: Shoulder wall

Surface course of shoulder wall (shoulder inner wall) section: the width of the shoulder part of the surface course is: hard shoulder $3.0 \mathrm{~m}+$ soil shoulder $0.15 \mathrm{~m}$, a total of $3.15 \mathrm{~m}$. The area of base course and subbase course shall be deducted according to the thickness of pavement and the back slope ratio of retaining wall.

\subsection{Shoulder pavement of fill section}

Fill road shoulder pavement is shown in Figure 4.

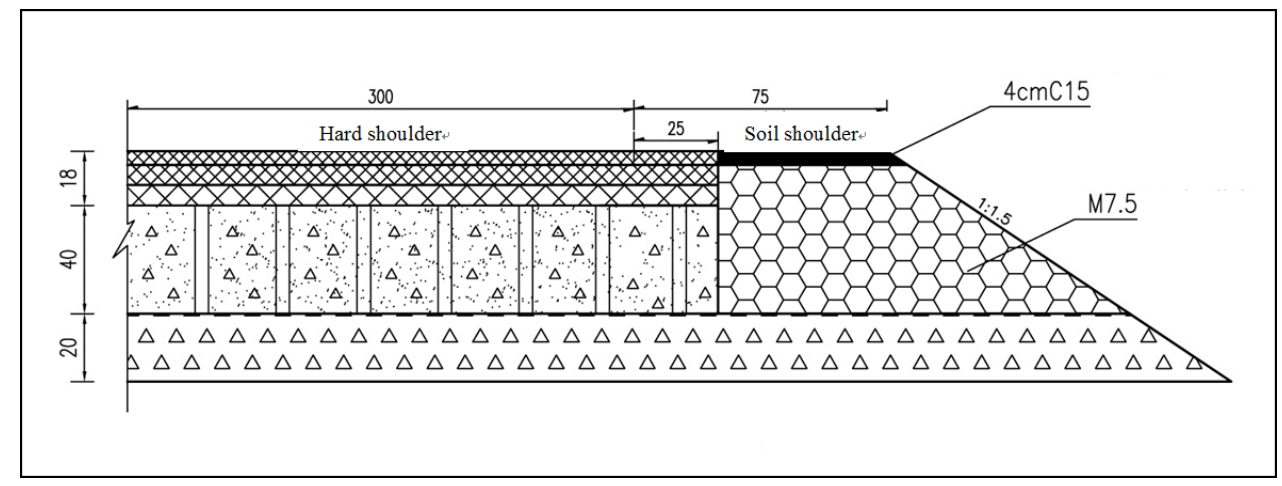

Fig 4: Fill road shoulder pavement

The width of pavement shoulder surface layer of fill section is $3.0 \mathrm{~m}+0.25 \mathrm{~m}=3.25 \mathrm{~m}$. The area of base course is the same as that of surface course. The area of subbase is calculated according to the fill slope and the average width of subbase according to the pavement thickness ( The area of subbase filling shoulder in the figure above can be calculated as $3+0.75+1.02=4.77 \mathrm{~m}$ in average width

\subsection{Median pavement}

Median pavement is shown in Figure 5.

ISSN: 0010-8189 


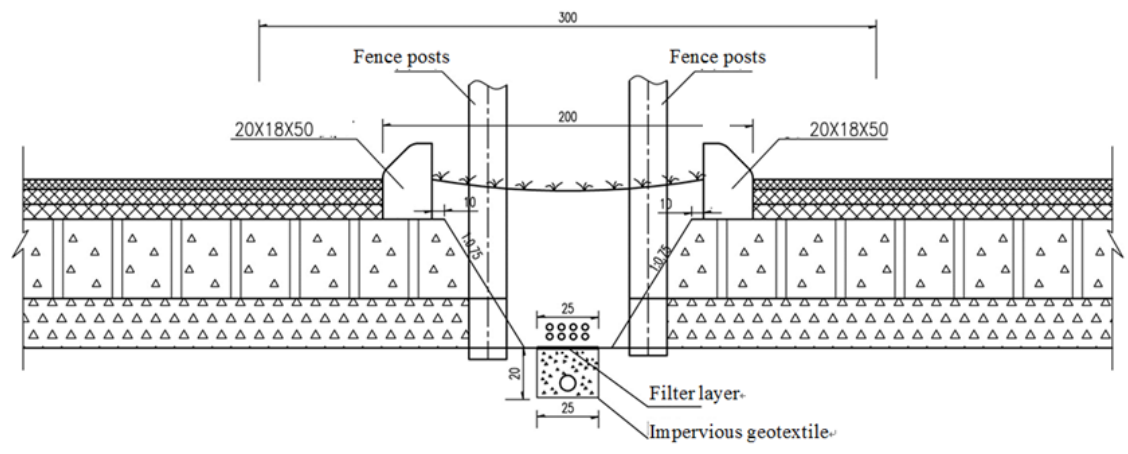

Fig 5: Median pavement

According to the above figure, the surface area of the median (half width) is calculated as $0.5 \mathrm{~m}$ wide. The width of intermediate base can be calculated as $0.5+0.2+0.1+0.15=0.95 \mathrm{~m}$. The middle subbase pavement can be calculated as: $0.5+0.2+0.1+0.375=1.175 \mathrm{~m}$ wide.

\subsection{Integral pavement area}

Integral pavement area can calculate as table 3.

Table 3 Calculation of integral pavement area

\begin{tabular}{|c|c|c|c|c|c|c|}
\hline $\begin{array}{c}\text { Different } \\
\text { sections }\end{array}$ & $\begin{array}{c}\text { Pavement } \\
\text { structure } \\
\text { layer }\end{array}$ & $\begin{array}{c}\text { Lane } \\
\text { width } \\
(\mathrm{m})\end{array}$ & $\begin{array}{c}\text { Shoulder width } \\
\text { of hard road } \\
(\mathrm{m})\end{array}$ & $\begin{array}{c}\text { Intermediate } \\
\text { bandwidth }(\mathrm{m})\end{array}$ & $\begin{array}{c}\text { Total } \\
\text { width } \\
(\mathrm{m})\end{array}$ & Remarks \\
\hline \multirow{2}{*}{$\begin{array}{c}\text { Excavation } \\
\text { section }\end{array}$} & Surface layer & 15 & 6 & 1 & 22 & According to the side \\
ditch
\end{tabular}

According to the route design specification, the opening of central divider should be set at the front and back of interchange, tunnel, super large bridge and service area facilities, as well as the separation (confluence) of integral subgrade and separated subgrade. The opening spacing of the median should be determined according to the needs, and the minimum spacing should not be less than $2 \mathrm{~km}$. The opening of the median should be set in the section with good visibility. If the opening is set in the curve section, the superelevation value of the radius of the circular curve should not be greater than $3 \%$.

\section{Conclusion}

At the stage of engineering feasibility study, the empirical estimation method is mainly used in the engineering feasibility study of most expressways and other grade highways in mountainous and hilly areas of Yunnan Province, such as Eshihong expressway, Kunchu expressway, Chuda expressway, etc. With the improvement of scientific and technological means. Application program promotion, the accuracy of basic data collection is improved and the estimation method of subgrade engineering quantity in the feasibility stage is constantly improved, which can greatly improve the efficiency and quality of engineering feasibility preparation.

ISSN: 0010-8189

www.converter-magazine.info 


\section{References}

[1] J.D. Doyle, I.L. Howard, W. J. Robinson, "Prediction of Absorbed, Inert, and Effective Bituminous Quantities in Reclaimed Asphalt Pavement," Journal of Materials in civil engineering, vol.24, no.1, pp.102-112, 2012.

[2] X. Sanchez, S.L. Tighe, "Steps towards the detection of reclaimed asphalt pavement in superpave mixtures," Road Materials and Pavement Design, vol.24, no.5, pp.1201-1214, 2019.

[3] N.S. Duong, J. Blanc, P. Hornych, et al., "Continuous strain monitoring of an instrumented pavement section," International Journal of Pavement Engineering, vol.10, no.12, pp.1435-1450, 2019.

[4] J.L. Wang, B. Wu, Q.C. Qin et al., "Study on initial flushing effect of two new permeable pavements," International Journal of Pavement Engineering, vol.22, no.2, pp.173-180, 2021.

[5] B. Kim, H. Lee, H. Park, et al., "Framework for Estimating Greenhouse Gas Emissions Due to Asphalt Pavement Construction," Journal of Construction Engineering and Management, vol.138, no.11, pp.1312-1321, 2012.

[6] M. F. Ahmad, S. Zaidi, A. Fareed, et al., "Assessment of sugar cane bagasse bio-oil as an environmental friendly alternative for pavement engineering applications," International Journal of Pavement Engineering, no.12, pp.1-12, 2021.

[7] N. Mashaan, N. Yusoff, I. Saad, "Using Waste Materials in Geotechnical and Pavement Engineering for Sustainable Construction,” Sustainability, vol.24, no.8, pp.28-37, 2021.

[8] S. B. Al-Ghurabi, B. H. Al-Humeidawi, "Comparative evaluation for the effect of particles size of reclaimed asphalt pavement (RAP) on the properties of HMA," Journal of Physics: Conference Series, vol.1895, no.1, pp.1-13, 2021.

[9] S. R. Kasu, S. Patel, A. R. Muppireddy, "Field experiments and numerical analysis of curling behavior of cast-in-situ short paneled concrete pavement on lean concrete base," International Journal of Pavement Engineering, no.8, pp.21-32, 2021.

[10] Z. Zhao, F. Xiao, S. Amirkhanian, "Recent applications of waste solid materials in pavement engineering," Waste Management, no.108, pp.78-105, 2020.

[11] P. M. Shah, M. S. Mir, "Application of Nano-Technology in Pavement Engineering: A Review," Canadian Journal of Civil Engineering, vol.47, no.3, pp.21-33, 2020.

[12] S. Perez, P. Maicelo, "Use of recycled asphalt as an aggregate for asphalt mixtures: literary review," Innovative Infrastructure Solutions, vol.6, no.3, pp.1-11, 2021. 